\title{
Energy expenditure and muscle activity during lying, sitting, standing, and walking in people with motor-incomplete spinal cord injury
}

\author{
Bart Dekker $^{1} \cdot$ Olaf Verschuren $^{1} \cdot$ Astrid C. J. Balemans ${ }^{1,2} \cdot$ Nadia Baart $^{1} \cdot$ Frank Tubbing $^{1} \cdot$ \\ Casper F. van Koppenhagen ${ }^{3}$ Marcel W. M. Post ${ }^{4,1}$
}

Received: 7 January 2018 / Revised: 28 May 2018 / Accepted: 29 May 2018 / Published online: 28 June 2018

(c) International Spinal Cord Society 2018

\begin{abstract}
Study design Cross-sectional exploratory study.

Objectives To determine oxygen uptake $\left(\mathrm{VO}_{2}\right)$, energy expenditure (EE), and muscle activity (MA) during lying (rest), sitting, standing, and walking among ambulatory individuals with spinal cord Injury (SCI) and to compare $\mathrm{VO}_{2}, \mathrm{EE}$, and MA between individuals with different levels of ambulation.

Setting Rehabilitation institution with a spinal cord injury unit.

Methods A total of 22 adults with motor-incomplete SCI, ten in a low-ambulation group (non-functional or household walker) and 12 in a high-ambulation group (community or normal walker). $\mathrm{VO}_{2}$ was measured using indirect calorimetry. EE was expressed in metabolic equivalent of task (MET). MA was measured using a wireless surface electromyography device.

Results Mean $\mathrm{VO}_{2}$ was $3.19 \mathrm{ml} / \mathrm{kg} / \mathrm{min}$. During lying and sitting, EE was below 1.5 METs for all participants. During standing, three participants of the low-ambulation group and none in the high-ambulation group showed MET values of $>1.5$. In the walking condition, all participants showed MET values above 1.5. MA during stance was higher compared to the sitting condition and significantly higher in the low-ambulation group compared to the high-ambulation group.

Conclusion Lying, supported- and unsupported sitting, without moving, appear to be sedentary behaviors for ambulatory individuals with a motor-incomplete SCI (MET values of $<1.5$ and a lack of MA). Walking, but not standing, is a moderate physical activity (>1.5 METs), which can be used by all individuals with motor-incomplete SCI to interrupt sedentary behavior.
\end{abstract}

Bart Dekker

b.dekker1987@gmail.com

1 Center of Excellence for Rehabilitation Medicine, Brain Center Rudolf Magnus, University Medical Center Utrecht, Utrecht University, and De Hoogstraat Rehabilitation, Utrecht, The Netherlands

2 Department of Rehabilitation Medicine, Amsterdam Movement Sciences, Amsterdam Public Health, VU University Medical Center, Amsterdam, The Netherlands

3 Department of Rehabilitation, Physical Therapy Science \& Sports, Brain Center Rudolf Magnus, University Medical Center Utrecht, Utrecht, The Netherlands

4 University of Groningen, University Medical Center Groningen, Department of Rehabilitation Medicine, Groningen, The Netherlands

\section{Introduction}

Physical activity has been associated with a reduced longterm cardiovascular disease risk in the spinal cord injured (SCI) population [1-3]. In addition, studies in healthy physically active individuals show, independent from activity levels, that prolonged periods of sedentary behavior are associated with a higher risk of type 2 diabetes, obesity, cardiovascular disease, and all-cause mortality [4-6]. Sedentary behavior is defined as any waking behavior characterized by an energy expenditure (EE) of $\leq 1.5$ metabolic equivalents of task (METs) while in a sitting, reclining, or lying posture [7]. Although all levels of physical activity, including sedentary time, in individuals with SCI has shown not to be directly associated with biomarkers of cardiometabolic health [8], it is probable that prolonged periods of sedentary behavior, in the long term, are 
associated with diseases in individuals with SCI, who spend most of their time in a sitting posture [9, 10]. Especially since they are known to have a higher risk to develop metabolic and cardiovascular diseases compared to the general population [11].

The definition of sedentary behavior encompasses both MET and posture [7]. The standard value of one MET represents a resting oxygen uptake $\left(\mathrm{VO}_{2}\right)$ of $3.5 \mathrm{ml} / \mathrm{kg} / \mathrm{min}$, which represents the average resting $\mathrm{VO}_{2}$ in the general population [12]. However, the resting $\mathrm{VO}_{2}$ in individuals with an SCI may be different from the general population due to their altered body composition [13]. Several studies reported that the resting metabolic rate in SCI individuals is overestimated by $5-35 \%$ when the standard value is used [14-16]. Therefore, most studies use the participant's own resting $\mathrm{VO}_{2}$ to calculate EE in METs during daily activities in the SCI population [15-19]. However, these studies mainly focused on individuals with motor-complete SCI and $\mathrm{EE}$ values during non-sedentary activities. The $\mathrm{EE}$ values associated with activities considered to be sedentary (sitting) and non-sedentary (standing/walking) in motor-incomplete SCI individuals therefore remain unknown. The motorincomplete SCI population is a very heterogeneous group with variety in the level of injury, and residual innervation. The severity of motor deficits is therefore extremely variable among people with motor-incomplete SCI. This may lead to differences in lean body mass and difficulty in performing certain activities that consequently may lead to variation in the measured $\mathrm{VO}_{2}$ and EE. Activities that are strenuous for individuals with more severe motor deficits might not be strenuous, and therefore not useful to interrupt sedentary behavior, for individuals with less severe motor deficits. Therefore, an evaluation of EE during a range of activities that approximate sedentary behavior among participants with a range of motor-incomplete SCI would provide valuable information about the actual physiological demand. For determining patient-specific values, in this heterogeneous group, categorization functional ambulation is necessary.

Muscle inactivity has negative consequences for health. Excessive sitting time, with contractile inactivity of the postural muscle groups, is associated with suppression of skeletal muscle lipoprotein lipase, which in turn is linked to decreased levels of HDL cholesterol, increased triglycerides levels, insulin resistance, and glucose [20, 21]. Observations in the general population suggest that brief interruptions of sedentary activities that require muscle activity (MA) lead to significant reductions in postprandial glucose and insulin levels, irrespective of the activity intensity [22, 23]. Thus, promoting even brief interruptions of sedentary time could be an important clinical intervention in the SCI population who spend most of their time in a sitting position. Both EE and MA are therefore important factors related to sedentary behavior.
An evaluation of the EE and MA profiles of individuals with SCI, during postures and activities that are assumed to represent or interrupt sedentary behavior (i.e., sitting, standing, and walking), would provide valuable information about their actual physiological demand. Therefore, the purpose of this study was to determine $\mathrm{VO}_{2}, \mathrm{EE}$, and MA during lying, sitting, standing, and walking among ambulatory individuals with motor-incomplete SCI. Because of the heterogeneity of the motor-incomplete SCI population, we categorized the study population on functional ambulation level to compare $\mathrm{VO}_{2}, \mathrm{EE}$, and MA.

\section{Methods}

\section{Study design}

This cross-sectional exploratory study was conducted at De Hoogstraat Rehabilitation, a rehabilitation institution with a SCI unit in the Netherlands. The Medical Ethics Committee of the University Medical Centre Utrecht reviewed the study protocol and concluded that this study did not fall under the scope of the Dutch Medical Research Involving Human Subjects Act (WMO). The study was subsequently approved by De Hoogstraat Rehabilitation, and informed consent was obtained from all included participants.

\section{Procedure}

Individuals with SCI visiting the outpatient clinic of De Hoogstraat Rehabilitation who fitted the inclusion and exclusion criteria were invited for this study. They were contacted by telephone and received written information. Those who consented for participation were tested on the day of their appointment at the outpatient clinic. The measurements were performed during working hours, dependent on the availability of the participants. They were asked not to consume food, drinks (other than water), or smoke for at least $4 \mathrm{~h}$ before the measurement. Furthermore, participants were asked not to participate in any sport or other vigorous physical activities $24 \mathrm{~h}$ before the measurement. Information regarding demographics, medical history, use of medication, and smoking was taken from medical charts and checked during the appointment.

Measurements were done in a fixed sequence: lying, unsupported sitting, supported sitting, standing, and walking. This order was used to minimize the need for transfers between the examination table and a chair. The knee angle of the participants during the sitting conditions was held at approximate $90^{\circ}$ by using an adjustable table and seat. Participants who used a walking aid in daily life were permitted to use one during the standing and walking 
conditions when necessary. All participants wore shoes during the standing and walking conditions to avoid different walking patterns compared to their normal life. The conditions lying, sitting without support, sitting with support, and standing lasted a minimum of $5 \mathrm{~min}$ and walking lasted a minimum of $6 \mathrm{~min}$. Walking was performed at a comfortable pace back and forth on a $15-\mathrm{m}$ course.

\section{Participants}

Eligible participants were older than 18 years of age on the date of the measurement, were able to understand Dutch, and had no cognitive impairment preventing them from performing simple tasks. All participants had a motorincomplete SCI, American Spinal Injury Association Impairment Scale $\mathrm{C}$ or $\mathrm{D}$, for at least 1 year, and were able to stand for $5 \mathrm{~min}$ and walk for at least $6 \mathrm{~min}$, with or without the use of an aid. Participants were excluded if they had a known allergy to electromyography (EMG) electrodes, known cardiovascular disease, pulmonary problems that would interfere with the EE measurements, or if they had another disease that could influence their standing and walking performance and/or EE, like cerebrovascular or neuromuscular diseases.

\section{Outcome measures}

Height was measured using a tapeline in stance, weight was measured using an electronic scale (Seca, Hamburg, Germany) calibrated to the nearest $0.1 \mathrm{~kg}$, and blood pressure was measured electronically using a sphygmomanometer (Omron Healthcare, Model M3, Kyoto).

The adapted Hoffer Functional Ambulation Scale was used by the first author to categorize the participants' level of functional walking ability [24]. This ordinal-level rating scale categorizes ambulatory status as normal ambulators, community ambulators, household ambulators, nonfunctional ambulators, and non-ambulators. Normal ambulators are without any mobility problems, not using any assistive devices for mobility. Community ambulators walk indoors and outdoors, and may need crutches, braces, or both. They may also use a wheelchair for longer distances. Household ambulators walk only in and around the house with walking devices. They may use a wheelchair for some indoor activities and use a wheelchair for all activities in the community. Non-functional ambulators are able to walk in a therapy session, but use a wheelchair in their everyday life. Because of the low numbers of participants per group, level of ambulation was dichotomized into two categories in the statistical analyses. The normal ambulators and community ambulators groups were merged into a high-ambulation group, and the non-functional ambulators and household ambulators groups were merged into a low-ambulation group.

Oxygen consumption was measured using indirect calorimetry. By indirect calorimetry, $\mathrm{VO}_{2}$ was measured and sampled at $10 \mathrm{~s}$ intervals. Indirect calorimetry is considered the gold standard for assessing the $\mathrm{VO}_{2}$ in the general population, as in the SCI population [15, 25]. In this study, the Cortex Metamax 3B system was used and data were analyzed with the Metasoft software (Samcon, Belgium). The Metamax is a valid and reliable system for measuring ventilatory parameters [26]. The system weighs about $1 \mathrm{~kg}$ and is comfortably worn on the chest. Participants wore a firm fitted facemask over mouth and nose, which was attached to a transmitting unit with gas analyzers. Prior to the measurement, or at least once a day, the volume analyzer was calibrated with a three-liter calibration pump. The gas analyzer was calibrated with two gasses of known mixture $\left(17 \% \mathrm{O}_{2}, 5 \%\right.$ $\mathrm{CO}_{2}$ ). Before the start of each measurement, the flow sensor was adjusted, thereby avoiding contact with breathing or draught. After installation of the Metamax and preparation of the EMG gear (which lasted about $60 \mathrm{~min}$ while the participant was in a lying position), the participants were asked to further acclimatize without talking in a lying position for $15 \mathrm{~min}$. To minimize variation, measurements of $\mathrm{VO}_{2}$ during each activity were maintained for at least $2 \mathrm{~min}$ after reaching a steady state (which means not more than $2 \mathrm{ml} / \mathrm{kg} / \mathrm{min} \mathrm{VO}_{2}$ difference in 1 min time) [27].

During all conditions, $M A$ of 12 muscle groups was measured using a wireless surface EMG device (Mega Electronics Ltd., eMotion Faros, Kuopio). Surface EMG is a valid method to measure muscle activation non-invasively [28]. Prior to electrode placement, the skin was shaved and cleaned with alcohol to optimize EMG signal transfer. The electrodes were placed parallel to the muscle fibers with a 20-mm distance between the electrodes. The placement of the electrodes was following the recommendations of the SENIAM group [29]. The 12 muscle groups measured were (left and right for all muscle groups): $\mathrm{m}$. vastus lateralis, m. tibialis anterior, m. soleus, m. biceps femoris, $\mathrm{m}$. gastrocnemius medialis, and $\mathrm{m}$. erector spinae. The EMG signal was recorded by amplification of the signal $(1000 \times)$, followed by an analog bandpass filtering (range $10-450 \mathrm{~Hz}$ ) and an analog to digital conversion with a sampling frequency of 1000 samples per second. Measurement of MA for each posture started when the EE was stable for $1 \mathrm{~min}$.

\section{Data analysis}

The EE and EMG data were processed offline with Matlab (Mathworks, Matlab 2013b, Massachusetts) and 
analyzed using SPSS version 24.0 (SPSS Inc., Chicago, Illinois).

\section{Oxygen consumption}

Oxygen consumption was determined as the mean $\mathrm{VO}_{2}$ measured in lying position and during the different activities for at least 2 min after a steady state was reached.

\section{Energy expenditure}

Mean values $( \pm \mathrm{SD})$ of $\mathrm{VO}_{2}(\mathrm{ml} / \mathrm{kg} / \mathrm{min})$ measured during the different activities were calculated. EE was expressed in METs. We defined 1 MET for every participant as his or her own resting $\mathrm{VO}_{2}$. The METs of each activity were calculated by dividing the mean $\mathrm{VO}_{2}$ during each activity by the resting $\mathrm{VO}_{2}$.

\section{Muscle activity}

Power spectra for all raw EMG signals per muscle group were calculated and plotted to check for contaminations due to movement artifacts, sensor noise (frequency median $>200 \mathrm{~Hz}$ ), ECG contamination, and power line interference $(50 \mathrm{~Hz})$. Thereafter, the following procedures were applied: a digital high-pass filter (2nd-order Butterworth filter) with a cut-off frequency of $30 \mathrm{~Hz}$, a digital band-stop filter (2nd-order ORR notch digital filter) around $50 \mathrm{~Hz}$ up to $500 \mathrm{~Hz}$ with steps of $50 \mathrm{~Hz}(50,100,150, \ldots 500 \mathrm{~Hz})$, and a correction for off-set of the signal by subtracting the mean and rectification of the filtered signal. In order to determine overall MA level, the left and right muscles were averaged. Because it is not feasible in persons with impaired muscle activation to perform a maximal voluntary contraction, the MA during activities was expressed as a percentage of the participant's MA during walking at a comfortable pace.

\section{Walking velocity}

Walking velocity $(\mathrm{m} / \mathrm{s})$ was calculated by dividing the walking distance (m) by the time (s) of the walking measurement.

Data were checked for normality using a Shapiro-Wilk test and by inspection of histograms and boxplots. The Unpaired sample $t$-test and Fishers test were used to check for differences between groups. As the variable $\mathrm{VO}_{2}$ was normally distributed, the results are presented in mean \pm 1 $\mathrm{SD}$. As the MET values were not normally distributed in the unsupported sitting and walking conditions, results are shown in median and inter-quartile range (IQR) or $95 \% \mathrm{CI}$. Depending on normality of the data, the Unpaired sample $t$-test or the Mann-Whitney $U$ test was used for comparing $\mathrm{VO}_{2}$, EE, and MA among the high-ambulation group and the low-ambulation group, for each activity.

\section{Results}

Thirty-five eligible participants were invited and 24 agreed to participate. Subsequently, one person could not participate because of physical problems with transfers, and one person had to postpone the appointment at the outpatient clinic. For all 22 participants, the EE for each activity could be measured adequately. Because of dysfunctional EMG gear, the EMG results of three participants could not be used for analysis. The descriptive statistics of the sample are shown in Table 1. There were no significant differences between the two groups, except for walking speed and the use of a walking aids.

\section{Oxygen consumption}

The mean $\mathrm{VO}_{2}$ uptake values during lying and all test conditions of the low-ambulation group and high-

Table 1 Descriptive characteristics of participants

\begin{tabular}{|c|c|c|c|c|}
\hline & & $\begin{array}{l}\text { Low-ambulation } \\
\text { group (mean; SD) }\end{array}$ & $\begin{array}{l}\text { High-ambulation } \\
\text { group (mean; SD) }\end{array}$ & Differences between groups \\
\hline & & $N=10$ & $N=12$ & \\
\hline Age & & $49.7(9.9)$ & $45.1(12.9)$ & $p=0.368(4.6,95 \%$ CI: -5.8 to 15.0$)$ \\
\hline \multirow[t]{2}{*}{ Gender } & Male & $7(70 \%)$ & $6(50 \%)$ & $p=0.420$ \\
\hline & Female & $3(30 \%)$ & $6(50 \%)$ & \\
\hline Height $(\mathrm{cm})$ & & $176.7(9.5)$ & $174.0(8.9)$ & $p=0.505(2.7,95 \%$ CI: -5.5 to 10.8$)$ \\
\hline Weight $(\mathrm{kg})$ & & $83.3(26.8)$ & $82.0(24.7)$ & $p=0.907(1.3,95 \%$ CI: -21.6 to 24.2$)$ \\
\hline BMI $\left(\mathrm{kg} / \mathrm{m}^{2}\right)$ & & $26.6(8.4)$ & $27.5(9.9)$ & $p=0.812(-0.95,95 \% \mathrm{CI}:-9.2$ to 7.3$)$ \\
\hline Walking velocity (m/s) & & $0.4(0.2)$ & $0.8(0.2)$ & $p=0.000(-0.47,95 \%$ CI: -0.7 to -0.3$)$ \\
\hline \multirow[t]{2}{*}{ Walking aid } & Yes & $9(90 \%)$ & $3(25 \%)$ & $p=0.004$ \\
\hline & No & $1(10 \%)$ & $9(75 \%)$ & \\
\hline
\end{tabular}




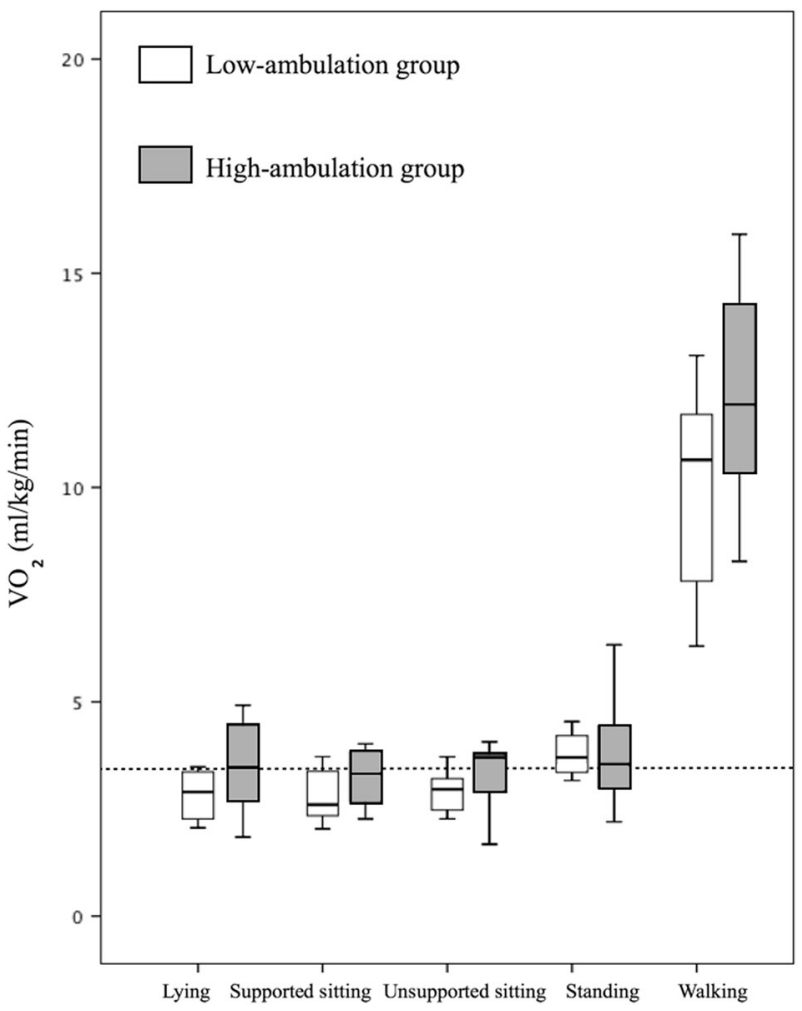

Fig. 1 Boxplot of $\mathrm{VO}_{2}$ uptake values $(\mathrm{ml} / \mathrm{kg} / \mathrm{min})$. The dotted line represents a $\mathrm{VO}_{2}$ value of $3.5 \mathrm{ml} / \mathrm{kg} / \mathrm{min}$

ambulation group are shown in Fig. 1 and Table 2. There is a significant difference only in the walking condition, between the groups. The mean resting $\mathrm{VO}_{2}$ for all participants was $3.19 \mathrm{ml} / \mathrm{kg} / \mathrm{min}$ (SD 0.87).

\section{Energy expenditure in METs}

The MET values for the low-ambulation group and the high-ambulation group are shown in Fig. 2 and Table 3. There were no significant differences in MET values between the two groups for all activities. During standing, three participants of the low-ambulation group and no participants of the high-ambulation group showed MET values $>1.5$ METs.

\section{Muscle activity}

MA scores among the low-ambulation group and the highambulation group during all test conditions are shown in Fig. 3. The total MA values of all the muscle groups (left and right) together are expressed as a percentage of the walking condition. The results are shown in median and IQR (Table 4). There were no significant differences in MA during test conditions considered sedentary (lying, unsupported sitting and supported sitting) between the low- and high-ambulation groups. During standing, the low-

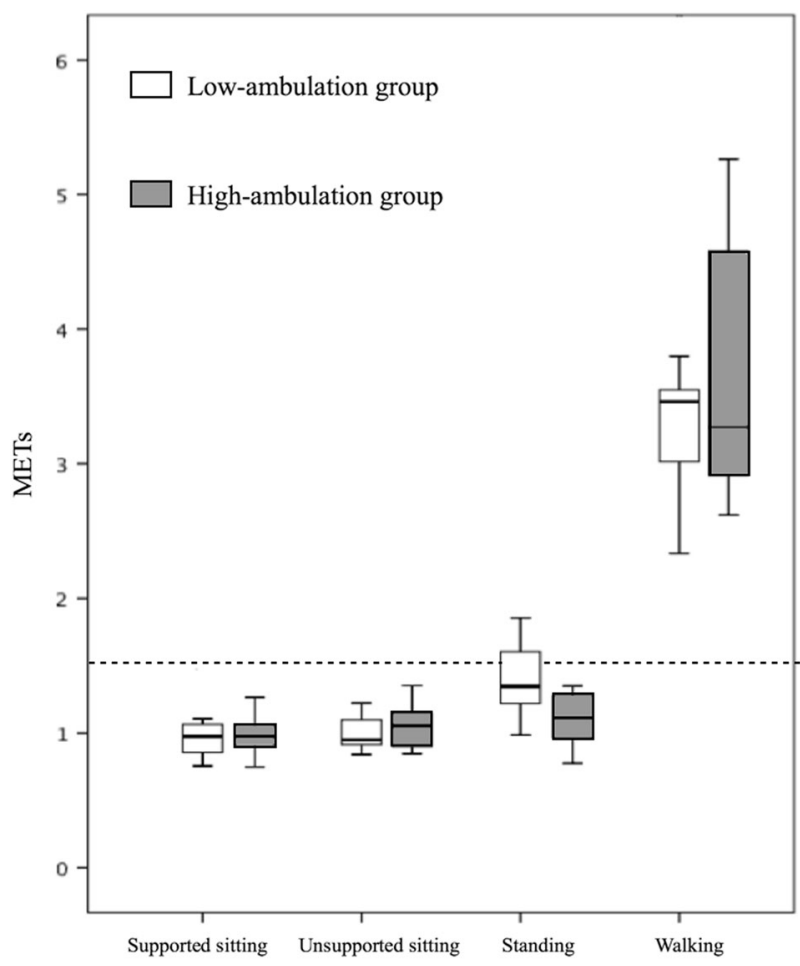

Fig. 2 Boxplot of MET values. The dotted line represents 1.5 METs

ambulation group had a significantly higher EMG score compared to the high-ambulation group.

\section{Discussion}

There were no differences in $\mathrm{VO}_{2}$ in rest or during the test conditions between groups. Participants with a lowambulation level showed significantly higher MA during standing compared to participants with a high-ambulation level, but without a significant difference in $\mathrm{EE}(p=0.056)$.

This is the first study to estimate the resting $\mathrm{VO}_{2}$ in a study group consisting of only people with motorincomplete SCI. We found a mean $\mathrm{VO}_{2}$ of $3.19 \mathrm{ml} / \mathrm{kg} / \mathrm{min}$ (SD 0.87) in the participants of our study with motorincomplete SCI. Studies on resting $\mathrm{VO}_{2}$ including people with complete SCI or mixed motor-complete and -incomplete $\mathrm{SCI}$ groups showed $\mathrm{VO}_{2}$ values between 2.47 and 3.2 $\mathrm{ml} / \mathrm{kg} / \mathrm{min}[15-18,25]$. Individuals with motor-incomplete injuries seem to have higher resting $\mathrm{VO}_{2}$ compared to those with motor-complete injuries [13, 16, 17]. This is probably due to less atrophy of the muscles and less loss of lean body mass below the level of injury after motor-incomplete SCI [13]. These differences in lean body mass and level of injury also exist within the motor-incomplete SCI population. Therefore, a difference in $\mathrm{VO}_{2}$ and $\mathrm{EE}$ is to be expected in participants with a different ambulation level. It 
Table $2 \quad \mathrm{VO}_{2}$ uptake values $(\mathrm{ml} / \mathrm{kg} / \mathrm{min})$

\begin{tabular}{llllll}
\hline Test condition & $\begin{array}{l}\text { Low-ambulation group } \\
(\mathrm{mean} ; \mathrm{SD})\end{array}=10$ & $\begin{array}{l}\text { High-ambulation group } \\
(\mathrm{mean} ; \mathrm{SD})\end{array}=12$ & $\begin{array}{l}\text { Total group (mean; } \\
\text { SD) } n=22\end{array}$ & $\begin{array}{l}p \text {-Value } \\
\text { Cean difference \& 95\% } \\
\text { Confidence Interval }\end{array}$ \\
\hline Lying & $2.85(0.53)$ & $3.48(1.03)$ & $3.20(0.87)$ & 0.082 & $-0.6, \mathrm{CI}:-1.3$ to 0.1 \\
Supported sitting & $2.80(0.63)$ & $3.35(0.92)$ & $3.10(0.83)$ & 0.128 & $-0.5, \mathrm{CI}:-1.3$ to 0.2 \\
Unsupported sitting & $2.92(0.49)$ & $3.64(1.17)$ & $3.32(0.97)$ & 0.085 & $-0.7, \mathrm{CI}:-1.5$ to 0.1 \\
Standing & $3.78(0.45)$ & $3.79(1.10)$ & $3.79(0.85)$ & 0.970 & $0.0, \mathrm{CI}:-0.8$ to 0.7 \\
Walking & $9.95(2.31)$ & $12.14(2.53)$ & $11.14(2.62)$ & 0.049 & $-2.2, \mathrm{CI}:-4.4$ to 0.0 \\
\hline
\end{tabular}

Table 3 MET values

\begin{tabular}{lllllll}
\hline Test condition & $\begin{array}{l}\text { Low- } \\
\text { ambulation } \\
\text { group } \\
\text { (median; } \\
\text { IQR) } n=10\end{array}$ & $\begin{array}{l}\text { High- } \\
\text { ambulation } \\
\text { group } \\
\text { (median; }\end{array}$ & $\begin{array}{l}\text { Total group } \\
\text { (median; } n=12\end{array}$ & $\begin{array}{l}\text { Mann-Whitney } U \text { IQR } n=22 \\
\text { value/ } \\
\text { standardized test } \\
\text { statistic }\end{array}$ & $\begin{array}{l}p \text {-Value } \\
\text { Mean } \\
\text { difference \& } \\
95 \% \\
\text { Confidence } \\
\text { interval }\end{array}$ \\
\hline $\begin{array}{l}\text { Supported } \\
\text { sitting }\end{array}$ & 0.98 & 0.98 & 0.98 & $U=61.0$, & 0.947 & 0.01 , CI: \\
Unsupported & $(0.84-1.07)$ & $(0.90-1.07)$ & $(0.87-1.07)$ & $z=0.07$ & & -0.15 to 0.17 \\
sitting & 0.95 & 1.06 & 1.01 & $U=65.0$, & 0.742 & -0.01 , CI: \\
Standing & $(0.91-1.13)$ & $(0.91-1.17)$ & $(0.91-1.14)$ & $z=0.33$ & & -0.18 to 0.17 \\
& $(1.35$ & 1.11 & 1.24 & $U=31.0$, & 0.056 & 0.25 , CI: 0.04 \\
Walking & 3.46 & $(0.94-1.29)$ & $(1.03-1.35)$ & $z=-1.91$ & & to 0.46 \\
& $(3.01-3.61)$ & $(2.90-4.67)$ & $(3.01-3.97)$ & $z=0.07$ & 0.947 & -1.12, CI: \\
& & & & & & -1.01 to 0.78
\end{tabular}

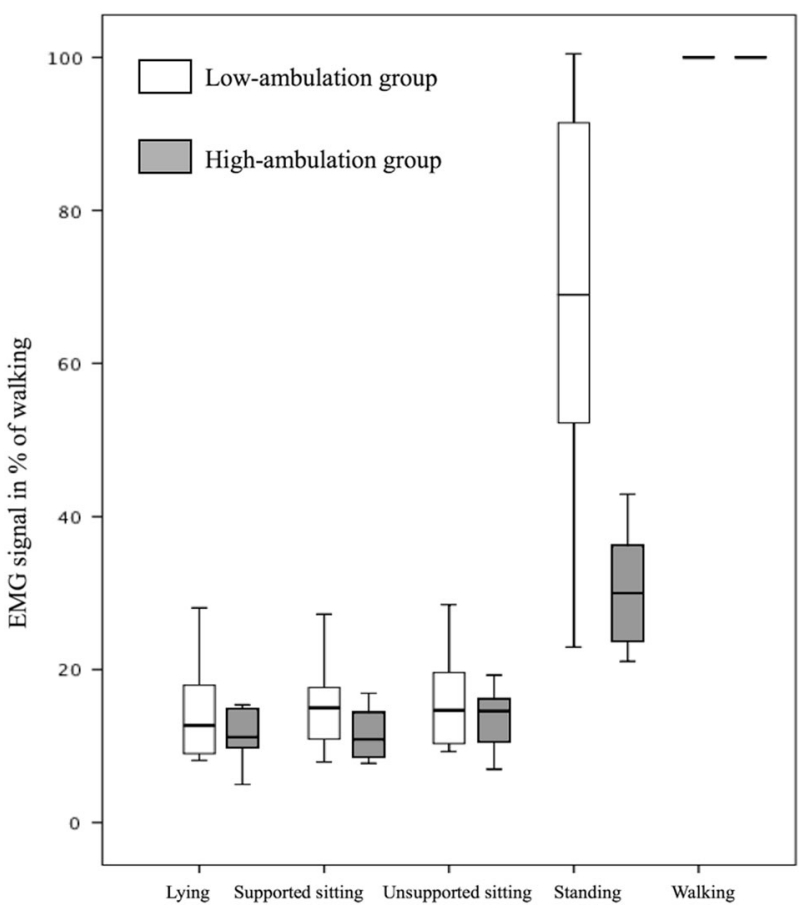

Fig. 3 Boxplot of muscle activity (all muscle groups) in \% of walking condition

is probable that participants with a high-ambulation level have more lean muscle mass and more residual muscle innervation. In this study, the resting $\mathrm{VO}_{2}$ in the low- ambulation group was lower compared to the highambulation group, but this difference was not significant. The small sample size and large variation in $\mathrm{VO}_{2}$ among the high ambulatory group could explain why this difference was not significant.

The EE values during supported sitting and unsupported sitting were approximately 1.0 METs. There were no differences between the two ambulation groups. Other studies determined EE during activities considered sedentary in motor-complete SCI (or a combination with motor-incomplete) and found higher values between 1.2 and 1.6 METs $[15,17,18]$. These higher values, compared with our findings, could be explained by the involvement of active movement of the upper body, trunk, and arms (desk work, computer work, reading), in these other studies and differences in study samples. Interestingly, these other studies showed that sitting or working in a sitting position is not or hardly enough to interrupt sedentary behavior ( $<1.5$ METs) in both people with motor-incomplete or motor-complete SCI $[15,17,18]$. Results from other studies in the general population were in line with our findings and found no significant differences in EE during supine and motionless sitting measurements $[30,31]$.

Only three participants in the low-ambulation group had an EE value $>1.5$ METs while standing. For these individuals in the low-ambulation group, standing requires more energy than described in the definition of sedentary 
Table 4 Muscle activity (all the muscle groups) in \% of walking condition

\begin{tabular}{|c|c|c|c|c|c|c|}
\hline Test condition & $\begin{array}{l}\text { Low-ambulation } \\
\text { group (median; IQR) } \\
n=10\end{array}$ & $\begin{array}{l}\text { High-ambulation } \\
\text { group (median; IQR) } \\
n=9\end{array}$ & $\begin{array}{l}\text { Total group } \\
\text { (median; IQR) } \\
n=19\end{array}$ & $\begin{array}{l}\text { Mann-Whitney } U \text { value/ } \\
\text { standardized test statistic }\end{array}$ & $p$-Value & $\begin{array}{l}\text { Mean difference \& } \\
\text { 95\% Confidence } \\
\text { Interval }\end{array}$ \\
\hline Lying & $12.7(8.94-20.50)$ & $11.0(7.62-14.93)$ & $12.09(9.01-15.37)$ & $\begin{array}{l}U=38.0 \\
z=-0.57\end{array}$ & 0.568 & $\begin{array}{l}4.75, \mathrm{CI}:-16.03 \text { to } \\
25.54\end{array}$ \\
\hline Supported sitting & $15.0(10.74-20.06)$ & $10.8(8.23-15.53)$ & $12.26(9.40-16.82)$ & $\begin{array}{l}U=27.0 \\
z=-1.47\end{array}$ & 0.142 & $\begin{array}{l}7.74, \mathrm{CI}:-11.79 \text { to } \\
27.27\end{array}$ \\
\hline $\begin{array}{l}\text { Unsupported } \\
\text { sitting }\end{array}$ & $14.7(10.30-21.81)$ & $14.3(9.43-17.44)$ & $\begin{array}{l}14.58 \\
(10.32-19.02)\end{array}$ & $\begin{array}{l}U=36.0 \\
z=-0.74\end{array}$ & 0.462 & $\begin{array}{l}7.04, \mathrm{CI}:-9.55 \text { to } \\
23.63\end{array}$ \\
\hline Standing & $69.0(50.56-92.48)$ & $30.3(23.74-37.10)$ & $\begin{array}{l}43.19(28.41 \\
-70.06)\end{array}$ & $\begin{array}{l}U=53.0 \\
z=-3.02\end{array}$ & 0.003 & $\begin{array}{l}38.60, \mathrm{CI}: 20.80 \text { to } \\
56.39\end{array}$ \\
\hline
\end{tabular}

behavior [7]. Although the difference with the highambulation group was non-significant $(p=0.056)$, standing seems to be more intense for individuals with a lower ambulation function. The participants in this study who used a walking aid in daily life were allowed to use a walking aid during the measurements, which could explain the low MET values during standing. Similarly, the study of Collins et al. [17] reported MET scores of only 1.17 MET in two motor-incomplete SCI during assisted standing with an walking aid.

For the walking condition, the MET values of both groups varied between 3 and 4.5 METs, which is moderateintensity activity (3-5.9 METs). The study of Collins et al. reported a mean MET score of 4.7 METs in nine motorincomplete male SCI individuals while walking [17]. Another interesting finding is that the EE during walking was similar in both levels of ambulation groups. This can be explained by the protocol used in this study. The walking velocity was not standardized, since participants were instructed to walk at a comfortable pace.

It is important to realize that there is no study available that studies the direct relation between the individualized MET values, which we use in this study, and cardiometabolic health biomarkers or long-term health benefits. This dimension remains to be analyzed.

MA during lying and sitting is similar in both groups. Another study found significant higher EMG activity levels in static trunk muscles in individuals with SCI relative to healthy controls during tasks like sitting [32]. The present study did not find a difference between the ambulatory groups, possibly due to the muscle groups measured (mostly leg and back muscles instead of trunk muscles per se). In future research, it will be interesting to include trunk and upper body muscles since individuals might activate these muscle groups for maintaining balance in a sitting position. The present study shows that there is a rise in MA during standing compared to sitting in both groups. Since we determine overall MA level and averaged the left and right muscles, we cannot differentiate between muscle groups. The MA during standing is the highest in the lowambulatory group. A study of Pesola et al. [20] found that participants having low total muscle inactivity time had clinically significant better outcomes of HDL cholesterol and triglycerides than the participants having high total muscle inactivity time, independent of moderate to vigorous physical activity time. It may be possible that in people with SCI with higher MA, cardiometabolic biomarkers can be positively altered, even when having an EE of $<1.5$ METs. Because the mechanisms underlying the negative health consequences of prolonged sitting may be directly attributable to muscle inactivity, it is important to establish how much MA is sufficient to attenuate these consequences. A study in healthy young adults showed that a 7-8-fold increase in MA led to an attenuation of postprandional Cpeptide, but not for other metabolic biomarkers [33]. At this time, we do not know how much MA is required to counteract the negative health consequences of sedentary behavior. But, activating large muscle groups is generally accepted as an interruption of sedentary behavior/time. A recent interesting study shows that low-frequency stimulation of the quadriceps and hamstrings increased $\mathrm{EE}$ above the resting baseline level, which might also be a feasible option to offset the negative side effects related to muscle inactivity after SCI [34].

There are some limitations to this study. It should be noted that the results from this cross-sectional study are not indicative of the cause and effect. Controlled studies are needed to determine the impact of sedentary behavior on cardiometabolic health in this study population. Second, this study is limited by the low number of participants and the great diversity of functional walking ability in the motor-incomplete SCI population. Third, we did not test all participants on the same time in the day which could have influenced the results. Fourth, we were not able to use a ventilated hood since we wanted to measure $\mathrm{VO}_{2}$ during more activities (i.e., sitting, standing, and walking), which is not possible in the ventilated hood setup. Fifth, the majority of previous studies have used longer time periods to asses 
resting $\mathrm{VO}_{2}$. This could result in an overestimation of the resting $\mathrm{VO}_{2}$. Sixth, the results are not generalizable for the whole population of people with motor-incomplete spinal cord injury since we did not include people without ambulatory function. In this study, the level of injury was left out of the analysis since we categorized the participants on level of functional walking ability. Our study population might have been too small to detect a significant betweengroup difference in $\mathrm{VO}_{2}$ and $\mathrm{EE}$ values. We suspect that when using a larger study group, the $\mathrm{VO}_{2}$ in rest and during activities will be significantly lower in participants with a lower ambulation level compared to participants with a higher ambulation level. Furthermore, comparing the METs values, based on a person's own resting $\mathrm{VO}_{2}$, we believe this will be significantly higher in participants with a lower level of ambulation. This means that the relative EE will be higher in the participants with a lower ambulation level.

Furthermore, moderate to vigorous physical activity should not be forgotten, since it not only has health benefits but also attenuates the health risks of high volumes of sedentary time [6, 35]. At last, MA was expressed as a percentage of walking MA during walking at a comfortable pace instead of expressing it as a percentage of maximal voluntary contraction, as this is not feasible in persons with impaired muscle activation. The level of MA during walking is higher in people with severe mobility limitation, and therefore the absolute difference in EMG between groups for the other activities might have been underestimated in this study.

\section{Conclusion}

Lying, supported- and unsupported sitting, without moving, are, according to the definition, sedentary behaviors for individuals with a motor-incomplete SCI (MET values of $<1.5$ and a lack of MA) as is the case for able-bodied individuals. Walking, but not standing, can be classed as a moderate physical activity ( $>3$ METS) in persons with motor-incomplete SCI. While walking could be used to interrupt prolonged periods of sedentary behavior in this population, the chronic effects over time on cardiometabolic health remain unknown.

\section{Compliance with ethical standards}

Conflict of interest The authors declare that they have no conflict of interest.

\section{References}

1. Bakkum AJ, Paulson TA, Bishop NC, Goosey-Tolfrey VL, Stolwijk-Swuste JM, van Kuppevelt DJ, et al. Effects of hybrid cycle and handcycle exercise on cardiovascular disease risk factors in people with spinal cord injury: a randomized controlled trial. J Rehabil Med. 2015;47:523-30.

2. Kim DI, Lee H, Lee BS, Kim J, Jeon JY. Effects of a 6-week indoor hand-bike exercise program on health and fitness levels in people with spinal cord injury: a randomized controlled trial study. Arch Phys Med Rehabil. 2015;96:2033-40 e1.

3. Nightingale TE, Walhin JP, Thompson D, Bilzon JLJ. Impact of exercise on cardiometabolic component risks in spinal cordinjured humans. Med Sci Sports Exerc. 2017;49:2469-77.

4. Biswas A, Oh PI, Faulkner GE, Bajaj RR, Silver MA, Mitchell MS, et al. Sedentary time and its association with risk for disease incidence, mortality, and hospitalization in adults: a systematic review and meta-analysis. Ann Intern Med. 2015; $162: 123-32$.

5. Duvivier BM, Schaper NC, Bremers MA, van Crombrugge G, Menheere PP, Kars M, et al. Minimal intensity physical activity (standing and walking) of longer duration improves insulin action and plasma lipids more than shorter periods of moderate to vigorous exercise (cycling) in sedentary subjects when energy expenditure is comparable. PLoS ONE. 2013;8:e55542.

6. Ekelund U, Steene-Johannessen J, Brown WJ, Fagerland MW, Owen N, Powell KE, et al. Does physical activity attenuate, or even eliminate, the detrimental association of sitting time with mortality? A harmonised meta-analysis of data from more than 1 million men and women. Lancet. 2016;388:1302-10.

7. Tremblay MS, Aubert S, Barnes JD, Saunders TJ, Carson V, Latimer-Cheung AE, et al. Sedentary Behavior Research Network (SBRN) - Terminology Consensus Project process and outcome. Int J Behav Nutr Phys Act. 2017;14:75.

8. Nightingale TE, Walhin JP, Thompson D, Bilzon JL. Biomarkers of cardiometabolic health are associated with body composition characteristics but not physical activity in persons with spinal cord injury. J Spinal Cord Med. 2017;1-10. e-pub ahead of print.

9. Buchholz AC, McGillivray CF, Pencharz PB. Physical activity levels are low in free-living adults with chronic paraplegia. Obes Res. 2003;11:563-70.

10. van den Berg-Emons RJ, Bussmann JB, Haisma JA, Sluis TA, van der Woude LH, Bergen MP, et al. A prospective study on physical activity levels after spinal cord injury during inpatient rehabilitation and the year after discharge. Arch Phys Med Rehabil. 2008;89:2094-101.

11. Myers J, Lee M, Kiratli J. Cardiovascular disease in spinal cord injury: an overview of prevalence, risk, evaluation, and management. Am J Phys Med Rehabil. 2007;86:142-52.

12. Jette M, Sidney K, Blumchen G. Metabolic equivalents (METS) in exercise testing, exercise prescription, and evaluation of functional capacity. Clin Cardiol. 1990;13:555-65.

13. Buchholz AC, McGillivray CF, Pencharz PB. Differences in resting metabolic rate between paraplegic and able-bodied subjects are explained by differences in body composition. Am J Clin Nutr. 2003;77:371-8.

14. Buchholz AC, Pencharz PB. Energy expenditure in chronic spinal cord injury. Curr Opin Clin Nutr Metab Care. 2004;7:635-9.

15. Holmlund T, Ekblom-Bak E, Franzen E, Hultling C, Wikmar LN, Wahman K. Energy expenditure in people with motor-complete paraplegia. Spinal Cord. 2017;55:796-7.

16. Lee M, Zhu W, Hedrick B, Fernhall B. Determining metabolic equivalent values of physical activities for persons with paraplegia. Disabil Rehabil. 2010;32:336-43.

17. Collins EG, Gater D, Kiratli J, Butler J, Hanson K, Langbein WE. Energy cost of physical activities in persons with spinal cord injury. Med Sci Sports Exerc. 2010;42:691-700.

18. Lynch MM, McCormick Z, Liem B, Jacobs G, Hwang P, Hornby TG, et al. Energy cost of lower body dressing, pop-over transfers, and manual wheelchair propulsion in people with paraplegia due 
to motor-complete spinal cord injury. Top Spinal Cord Inj Rehabil. 2015;21:140-8.

19. Nevin AN, Nguyen K, Atresh S, Vivanti A, Hickman IJ. Effective management of spasticity and impacts on weight change and resting energy expenditure in a female with spinal cord injury: a case report. Spinal Cord Ser Cases. 2017;3:17057.

20. Pesola AJ, Laukkanen A, Tikkanen O, Sipila S, Kainulainen H, Finni T. Muscle inactivity is adversely associated with biomarkers in physically active adults. Med Sci Sports Exerc. 2015;47: 1188-96.

21. Hamilton MT, Hamilton DG, Zderic TW. Role of low energy expenditure and sitting in obesity, metabolic syndrome, type 2 diabetes, and cardiovascular disease. Diabetes. 2007;56:2655-67.

22. Benatti FB, Ried-Larsen M. The effects of breaking up prolonged sitting time: a review of experimental studies. Med Sci Sports Exerc. 2015;47:2053-61.

23. Bergouignan A, Latouche C, Heywood S, Grace MS, ReddyLuthmoodoo M, Natoli AK, et al. Frequent interruptions of sedentary time modulates contraction- and insulin-stimulated glucose uptake pathways in muscle: Ancillary analysis from randomized clinical trials. Sci Rep. 2016;6:32044.

24. Verhoef M, Barf HA, Post MW, van Asbeck FW, Gooskens RH, Prevo AJ. Functional independence among young adults with spina bifida, in relation to hydrocephalus and level of lesion. Dev Med Child Neurol. 2006;48:114-9.

25. Nevin AN, Steenson J, Vivanti A, Hickman IJ. Investigation of measured and predicted resting energy needs in adults after spinal cord injury: a systematic review. Spinal Cord. 2016;54:248-53.

26. Macfarlane DJ, Wong P. Validity, reliability and stability of the portable Cortex Metamax 3B gas analysis system. Eur J Appl Physiol. 2012;112:2539-47.
27. Verschuren O, de Haan F, Mead G, Fengler B, Visser-Meily A. Characterizing energy expenditure during sedentary behavior after stroke. Arch Phys Med Rehabil. 2016;97:232-7.

28. Murley GS, Menz HB, Landorf KB, Bird AR. Reliability of lower limb electromyography during overground walking: a comparison of maximal- and sub-maximal normalisation techniques. J Biomech. 2010;43:749-56.

29. Hermens HJ, Freriks B, Disselhorst-Klug C, Rau G. Development of recommendations for SEMG sensors and sensor placement procedures. J Electromyogr Kinesiol. 2000; 10:361-74

30. Levine JA, Schleusner SJ, Jensen MD. Energy expenditure of nonexercise activity. Am J Clin Nutr. 2000;72:1451-4.

31. Miles-Chan JL, Sarafian D, Montani JP, Schutz Y, Dulloo AG. Sitting comfortably versus lying down: is there really a difference in energy expenditure? Clin Nutr. 2014;33:175-8.

32. Wang YJ, Li JJ, Zhou HJ, Liu GL, Zheng Y, Wei B, et al. Surface electromyography as a measure of trunk muscle activity in patients with spinal cord injury: a meta-analytic review. J Spinal Cord Med. 2016;39:15-23.

33. Altenburg TM, Rotteveel J, Dunstan DW, Salmon J, Chinapaw MJ. The effect of interrupting prolonged sitting time with short, hourly, moderate-intensity cycling bouts on cardiometabolic risk factors in healthy, young adults. J Appl Physiol (1985). 2013;115:1751-6.

34. Woelfel JR, Kimball AL, Yen CL, Shields RK. Low-force muscle activity regulates energy expenditure after spinal cord injury. Med Sci Sports Exerc. 2017;49:870-8.

35. van der Ploeg HP, Hillsdon M. Is sedentary behaviour just physical inactivity by another name? Int J Behav Nutr Phys Act. 2017; $14: 142$ 